\title{
Foreword by Margaret K. Lewis
}

I first met James Hou when he was a Visiting Scholar at Columbia University. Mr. Hou joined a group of New-York-area law professors for our annual workshop on works-in-progress on Chinese law. What quickly became apparent was the wealth of legal expertise and practical experience that he possessed. It was a long day around a table discussing draft papers, but I wanted to keep asking Mr. Hou questions. Exchanging name cards was not just a pleasantry: it was my means of tracking him down so I could further pick his brain.

Mr. Hou is not only a scholar, but also a practitioner who is a licensed patent attorney in Taiwan. His trifecta of studies in Taiwan, China, and the United States has equipped him with enviable knowledge of three different legal systems. "On the Industrialization of Pharmaceutical Patents Special Research on Patent Law in China" melds this knowledge into a single book. I am writing this foreword in the summer of 2020, a time when the physical movement across borders is challenging both for health and political reasons. Mr. Hou's firm grounding in the law and practice of these three jurisdictions is all the more valuable as it becomes increasingly difficult to replicate his experience.

In this book, Mr. Hou explores the role of intellectual property rights in China's pharmaceutical industry. Pharmaceutical patents are, to put it mildly, a highly specialized area of law. But Mr. Hou thankfully provides an accessible entry point for non-specialists. He begins by explaining foundational concepts in patent law. He then turns to explaining why the patent system is so important to the pharmaceutical industry in particular.

Mr. Hou does not limit himself to the nuts-and-bolts of the legal regime for patents. Rather, he brings to the topic a policy perspective, asking how to balance the interests of patented drug developers, generic drug developers, and drug users. He further analyzes the business side of the pharmaceutical industry and the important role that this industry plays in the government's economic planning. In presenting this holistic view, Mr. Hou argues that, in order to truly upgrade and innovate the pharmaceutical industry, China must start with the legal system, with particular focus on patents.

The book concludes with thoughts on the industrialization of pharmaceutical patents from a broad economic perspective. He also provides concrete recommendations on ways China can promote the commercialization of pharmaceutical patents, such as learning from the U.S. litigation process and case management system. 
There is also plenty in the legal weeds for the more specialized reader. Mr. Hou analyzes a number of government directives, such as the "Opinions on Conducting the Consistency Evaluation of Quality and Efficacy of Generic Drugs" and "Technical Guidelines for Accepting Data from Overseas Clinical Trials of Drugs." He describes in detail the current legal framework and then shows how there remain gaps that must be filled to energize China's pharmaceutical industry.

While the title describes the scope as patent law "in China," Mr. Hou also provides a comparative perspective to China's patent system by drawing on his knowledge of U.S. patent laws and regulations. He is well positioned to tackle this task. In addition to his time visiting at Columbia University, Mr. Hou also was a Visiting Researcher at UC Berkeley Law and earned an LLM from the University of Pennsylvania. He is further licensed to practice law in New York.

My mentor Jerome A. Cohen wisely warns that the worst kind of comparative law scholarship compares one country's theory with another country's practice. Mr. Hou recognizes these limitations, explaining in Chapter 3 that the "book takes a more policy-oriented approach, concerned with the logic of thinking behind the legal systems of the two countries [China and United States]." He seeks out discrete illustrative points of comparison to provide insights and ideas, while avoiding broad-brush comparisons that reduce different legal systems to one-dimensional caricatures. Mr. Hou also weaves in references to Taiwan to complement his comparative discussion and even draws on India's experience.

While the book is about law, Mr. Hou recognizes law's limitations. He explains why laws are necessary but not sufficient for the industrialization of pharmaceutical patents: policy support and cultural transformation are also necessary. In my work studying China's legal system, I am reminded again and again how looking beyond the formal law is particularly important when understanding the workings of the party-state of the People's Republic of China.

Mr. Hou wrote the bulk of the book manuscript prior to the outbreak of COVID-19, though he includes updates into January 2020. The issues he addresses in the book have tremendous importance as the world scrambles to find a vaccine, as well as pharmaceuticals that might temper the severity of the virus in those who become infected. This race is bringing to the fore the strengths and weaknesses of various countries' environments for research and development.

The COVID-19 era is also showcasing the complex interactions between governments and the private sector: all desire to achieve pharmaceutical breakthroughs, but who will have rights to the economic benefits of those breakthroughs is subject to push-and-pull among various players. Mr. Hou's 
work demonstrates how law plays a critical, but not exclusive, role in shaping such interactions. "On the Industrialization of Pharmaceutical Patents Special Research on Patent Law in China" provides a grounding in the relevant law that is necessary to grapple with the pressing questions surrounding COVID-19 that span law and policy.

Finally, I note that Mr. Hou omits criminal law from the discussion because there is only so much one can do justice to in a single book. As a scholar who writes much on criminal law, however, I personally hope that this is not the last book foreword that I write for him. I would like to see a sequel on the criminal law aspects. In the meantime, I will continue to use that name card to track him down and benefit from his wealth of knowledge. And I am grateful this book is bringing that knowledge to a wide audience.

Margaret K. Lewis

Professor of Law, Seton Hall University 